\title{
Measurement and calculation of polymeric scale inhibitor concentration in water
}

\author{
A.N. Markin, ${ }^{1,2}$ S.V. Sukhoverkhov, ${ }^{2}$ P.A. Zadorozhny, ${ }^{2}$ N.V. Polyakova ${ }^{2}$ \\ and A.V. Brikov ${ }^{3 *}$ \\ ${ }^{1}$ Nizhnevartovsk branch of Federal State Budget Educational Institution of Higher \\ Education "Industrial University of Tyumen", Zapadny promyshlenny yzel, Panel 20, \\ Lenina str. 2/P, bld. 9, Nizhnevartovsk, Tumen oblast, Khanty-Mansi Autonomous \\ Area-Yugra, 628616 Russian Federation \\ ${ }^{2}$ Federal state-financed organization of science Institute of Chemistry Far-East \\ department of Russian Academy of Sciences, 100-letya Vladivostoka avenue, 159, \\ 690022 Vladivostok, Russian Federation \\ ${ }^{3}$ JSC "Neftegazholding”, Arbatskaya ploshchad, 1, 119019 Moscow, Russian Federation \\ *E-mail: alex_v_brikov@list.ru
}

\begin{abstract}
Mineral scale deposition is a well-known problem within the oil and gas industry. Scaling leads to tubing diameter reduction, failure of well equipment, reduction of heater-treaters performance, severe corrosion of tubing and piping internal surface, etc. One of the most widely used methods of scale prevention in oil and gas industry is application of scale inhibitors. A large class of scale inhibitors is presented by reagents with polymers as an active base, the so-called polymeric scale inhibitors. For the successful application of any scale inhibitor, the concentration of applied regents in water phase of an oil production system shall be monitored. However, there is no standard method for analysis of polymeric scale inhibitor concentration in the water phase of oil and gas production systems. Using of energy-dispersive X-ray fluorescence analysis, CHNS-analysis, IR-spectroscopy, pyrolytic chromatography mass spectrometry, low-resolution chromato-mass spectrometry and high performance liquid chromatography, the composition of SCW85370 scale inhibitor (SI) was studied. It was found that scale inhibitor consists of a high molecular sulphated poly acrylic acid. A method for analysis of SCW85370 concentration in water was developed. The lower detection limit of the method does not exceed $3 \mathrm{mg} / \mathrm{dm}^{3}$. Practical results obtained using this method are provided. A formula for calculation of scale inhibitor concentration in formation water produced after scale inhibitor squeeze into formation is proposed. The formula allows the SI concentration to be calculated at any point of time using following data: volume of SI solution squeezed, volume of water squeezed, well water flow rate. It is shown that experimental data is well characterized by the suggested formula.
\end{abstract}

Received: March 29, 2018. Published: June 8, 2018

doi: $\underline{10.17675 / 2305-6894-2018-7-2-10}$ 
Key words: energy-dispersive X-ray fluorescence, CHNS analysis, IR spectroscopy, pyrolytic chromatography mass spectrometry, low-resolution chromatography mass spectrometry, high performance liquid chromatography, scale inhibitor, squeeze, residuals analysis.

\section{Introduction}

Mineral scale deposition leads to severe problems for oil and gas production: scaling of tubing - reduction of tubing internal diameter as a result of mineral scale deposition with consequent reduction of production, failure of well equipment (pumps and instruments); reduction of heater-treaters performance; severe corrosion of tubing and piping internal surface (in the areas of local scale deposition removal and under scale deposits) [1].

One of the most widely used methods of scale prevention in oil and gas industry is application of scale inhibitors (SI) [1-5].

The main criteria of SI effectiveness is the absence of downhole equipment failures in the protected wells. However, "waiting" for a failure could potentially take $100 \ldots 700$ days. During that time, only one (indirect) method of SI efficacy control exists. This method is analysis of the SI residual concentration in the water phase of the treated well $[1,2,4]$. Thus, effective application of an SI requires a method for its analysis in water to be available. It means that development of methods for SI concentration analysis in water is a critical task.

Phosphonates (phosphonic acids, esters and salts of phosphonic acids, etc.) are the active base of the majority of SI $[1,4,5]$. Reliable analytical methods are available for determination of the concentrations of such SI in water $[1,2,4,6]$. These methods are based on oxidation of phosphonates to orthophosphates with subsequent reduction to a phosphomolybdic acid and further to a molybdenum blue complex and photometric determination of the latter.

A large class of SI is presented by reagents with polymers as an active base, the so called polymeric SI [5]. There is no standard method for analysis of polymeric SI concentration in water phase of oil and gas production systems [7].

The paper describes a method of polymeric SI concentration analysis in water developed by the authors and practical results obtained using this method.

\section{Experimental description and results obtained}

A necessary step of polymeric SI concentration analysis is the identification of the nature of active base of the inhibitor.

To isolate the polymer from SI SCW85370 (manufactured by Baker Hughes), a sample was dried at $105^{\circ} \mathrm{C}$ (a dry residue was obtained). The dry residue was washed with ethyl alcohol and dried at $80^{\circ} \mathrm{C}$. The appearance of the polymer obtained from SI SCW85370 is shown in Figure 1. 


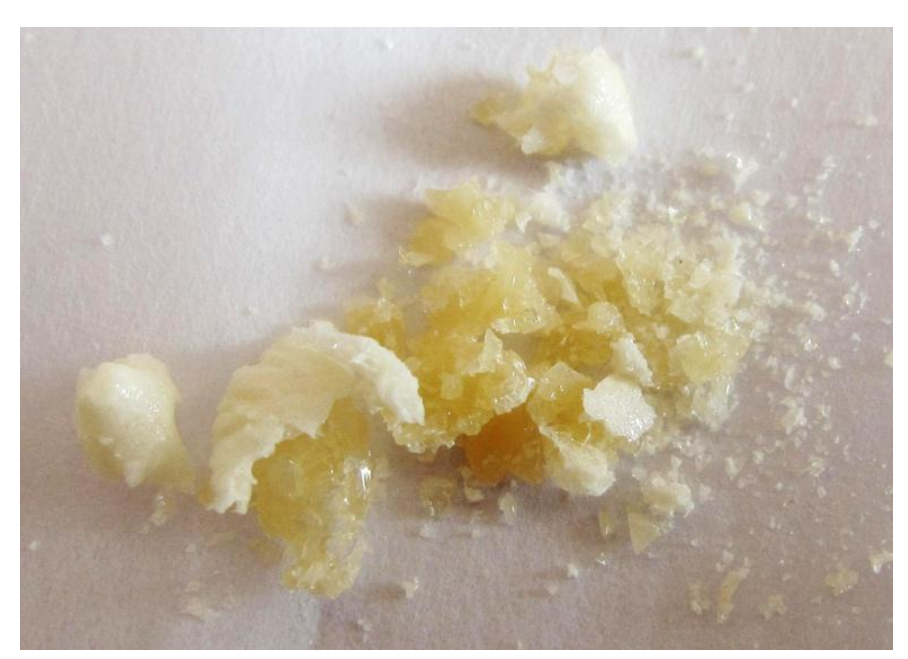

Figure 1. Polymer obtained from SI SCW85370.

The melting point of the polymer was determined using Barloworld Scientific Stuart SMP10 apparatus. It was found to be $95-100^{\circ} \mathrm{C}$.

The elemental composition of the polymer was determined by means of X-ray fluorescence analysis method (XRFA) [8,9]. As per XPFA data the polymer consists of carbon $(40.6 \%)$, potassium $(25.1 \%)$, sodium $(20.0 \%)$, sulfur $(8.8 \%)$, chorine $(5.9 \%)$ and phosphorous $(0.4 \%)$. It shall be mentioned that XRFA does not take into account the concentration of light elements such as $\mathrm{H}, \mathrm{B}$, and $\mathrm{N}$.

In order to specify the elemental composition of the polymer, CHNS-analysis was conducted using a Eurovector EuroEA3000 CHNS-analyzer. The results are provided in Table 1.

Table 1. Results of CHNS-analysis of the polymer from SI SCW85370.

\begin{tabular}{ccc}
\hline \multirow{2}{*}{ Element } & \multicolumn{2}{c}{ Concentration } \\
\cline { 2 - 4 } & \% wt. & \% mol \\
\hline $\mathrm{C}$ & 21.65 & 1.80 \\
$\mathrm{H}$ & 3.32 & 3.29 \\
$\mathrm{~N}$ & 0.00 & 0.00 \\
$\mathrm{~S}$ & 7.27 & 0.23 \\
\hline Mole ratio $\mathrm{C}: \mathrm{H}: \mathrm{N}: \mathrm{S}$ & & $1.00: 1.83: 0.00: 0.13$ \\
\hline
\end{tabular}

For identification of the polymer nature IR-spectrometry [10-12] and pyrolytic chromatography mass spectrometry (Py-GC-MS) were used [13-16].

IR spectra were obtained with IR spectrophotometer with Fourier transformation Shimadzu IRAffinity-1S with DRS-8000 accessory. Processing of IR spectra and identification of compounds was conducted with LabSolution IR Ver. 2.11 software. 
Library search of the spectra showed that the IR spectrum of the polymer is similar to the IR spectrum of a sodium salt of polyacrylic acid (76.7\% matching), as well as a sodium salt of polyethylenesulphonate (71.3\% matching). That allowed us to assume that the polymer tested is sulphated polyacrylic acid.

Pyrolysis was performed using a chromatography mass spectrometer Shimadzu GCMS QP-2010 with a Double-Shot Pyrolyzer PY-2020iD. The pyrolysis temperature was $600^{\circ} \mathrm{C}, \mathrm{PY} / \mathrm{GC}$ interface temperature was $320^{\circ} \mathrm{C}$. An Ultra ALLOY-5MS column was used for separation of the pyrolysis products with temperature programming from $40^{\circ} \mathrm{C}$ to $360^{\circ} \mathrm{C}$ (gradient $20^{\circ} \mathrm{C} / \mathrm{min}$, carrier-gas - helium). The interface temperature was $280^{\circ} \mathrm{C}$, the ion source temperature was $250^{\circ} \mathrm{C}$, the potential of the detector was $1 \mathrm{kV}$, mass range $(\mathrm{m} / \mathrm{z})$ 35-800. Comparison of the pyrograms was performed using the F-Search "All-InOne" Ver. 3.10 software. The Py-GC-MS confirmed that the polymer of SI SCW85370 was similar to polyacrylic acid (91\% matching) (Figure 2).

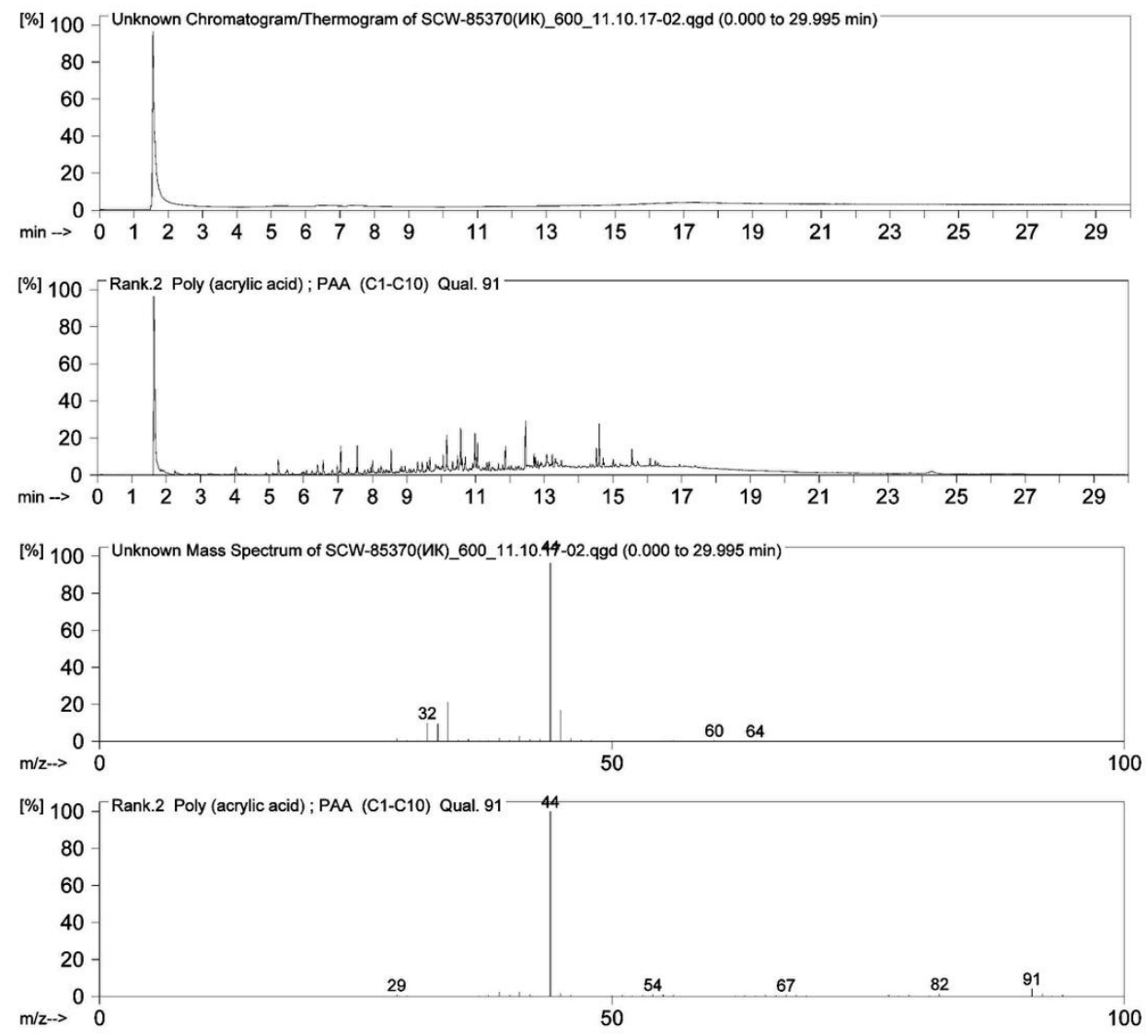

Figure 2. The pyrograms and full mass spectra of the polymer of the scale inhibitor SCW85370 and the polyacrylic acid form library of F-Search "All-In-One" Ver. 3.10.

Based on the data obtained by the XRFA, CHNS-analysis, IR-spectrometry and PyGC-MS, the authors concluded that the polymer of SI SCW85370 is a mixture of the 
potassium-sodium salts of sulphated polyacrylic acid. That is why it was decided to measure the concentration of SI SCW85370 in water by a HPLC technique $[17,18]$.

The HPLC analysis was conducted using a liquid chromatograph Shimadzu LC-20A with UV-detector SPD-20A (wavelength $200 \mathrm{~nm}$ ). Separation was carried out by two consecutively connected analytical columns Shimadzu FLC-ODS $(50 \times 4.6 \mathrm{~mm})$ and Shodex Asahipak GF-620 HQ, the column temperature was $40^{\circ} \mathrm{C}$, the eluent was acetonitrile/water (10/90), and the rate of the mobile phase was $0.8 \mathrm{~cm}^{3} / \mathrm{min}$. To measure the concentration, the system was calibrated using SI SCW85370 aqueous solutions with different concentrations (Figure 3). The lower detection limit of the method does not exceed $3 \mathrm{mg}$ of SI SCW85370 trade form in $1 \mathrm{dm}^{3}$ of water. For determination of the molecular mass the system was calibrated with a Pullulan Shodex P-82 kit and Blue Dextran 2000.

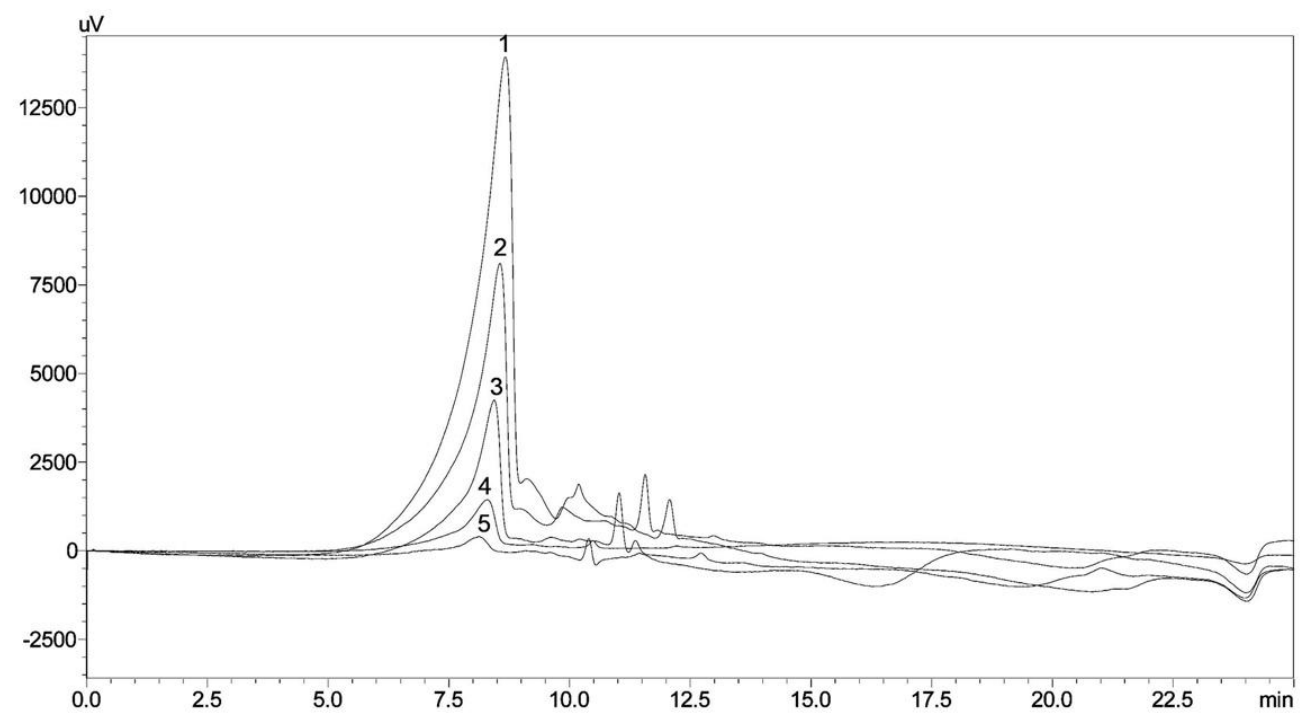

Figure 3. The chromatogram of aqueous solutions of the SCW85370 scale inhibitor. Concentrations of SI $\left(\mathrm{mg} / \mathrm{dm}^{3}\right): 1-100,2-50,3-25,4-10,5-3$.

The water samples from oil production systems usually contain hydrocarbons (from 10 to $500 \mathrm{mg} / \mathrm{dm}^{3}$ ). In order to prevent contamination of an analytical column with hydrocarbons, a Shimadzu FLC-ODS pre-column was included into the analytical set up. Figure 4 shows the chromatogram of water samples from a production well treated with SI SCW85370. The average molar mass $M_{\mathrm{w}}$ of the polymer from SI SCW85370 was $1500 \mathrm{kDa}$. 


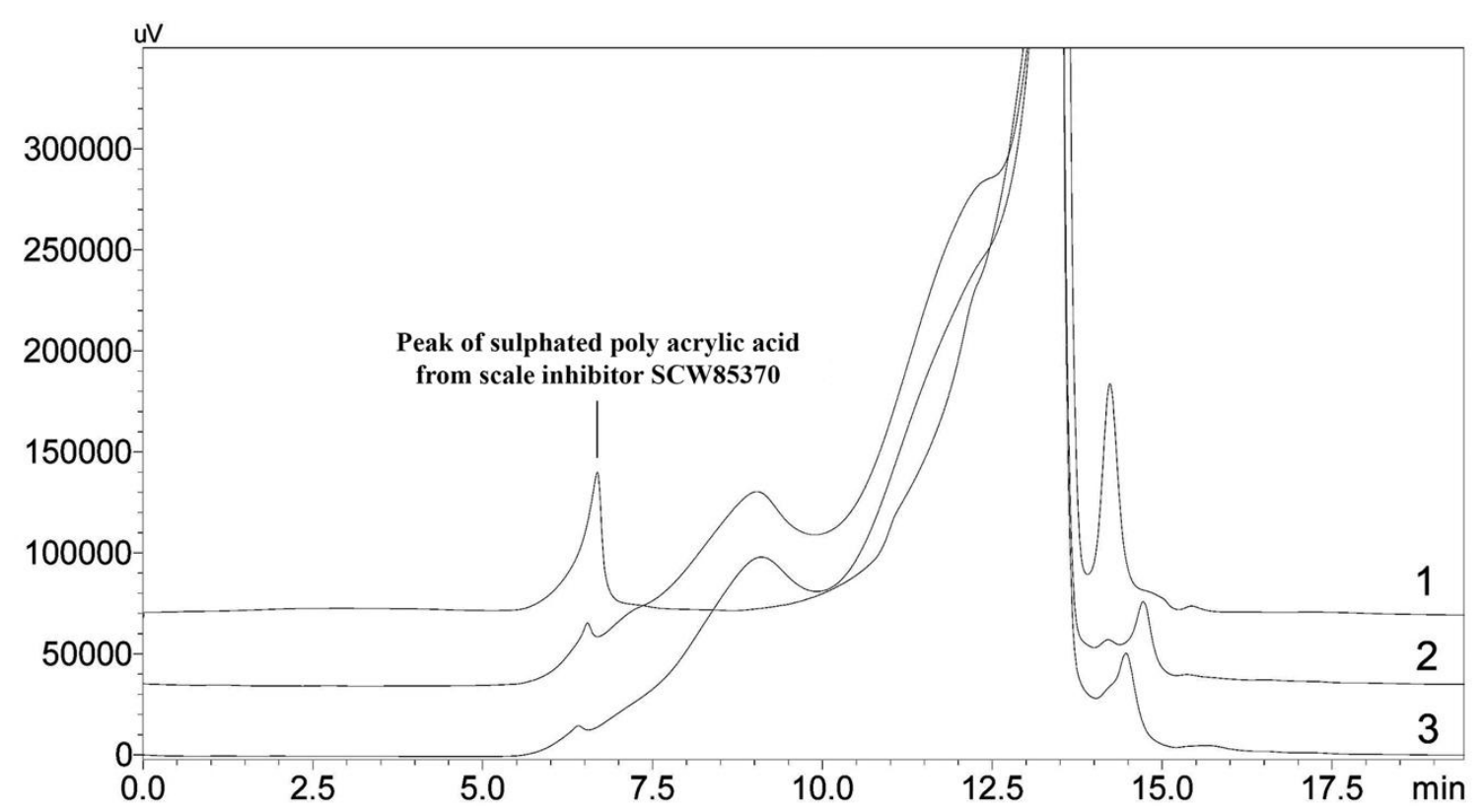

Figure 4. The chromatogram of water samples from the production well treated with SI SCW85370. Concentration of SI $\left(\mathrm{mg} / \mathrm{dm}^{3}\right): 1-876,2-408,3-200$.

Below the study of back-production of SI SCW85370 from the production well treated is provided. The concentration of SI SCW85370 in water was obtained using the method developed.

\section{Practical application of the method developed}

To protect electrical submersible pumps and tubing from scale deposition, the scale inhibitor water solution squeeze into formation is widely applied [1, 3, 19]. During the squeeze the SI is absorbed into a formation rock and further is gradually back-produced from the formation together with water preventing scale deposition. In this way the formation is used as a natural dozer. In order to make formation to be a dozer (the time of SI back-production to be $30 \ldots 150$ days but not several days), the SI solutions need to be squeezed deeply into the formation. To do that, right after the SI aqueous solution squeeze into formation, an additional batch of water is squeezed. Global experience in this field shows that for effective adsorption the scale inhibitor solution shall be squeezed into the formation for $\sim 2 \mathrm{~m}$.

After SI squeeze, its concentration in the produced water reduces rapidly in the first 2-7 days after the well start-up. Then the reduction in concentration slows down and the SI concentration remains practically unchanged for a long period (Figure 5) [1]. 


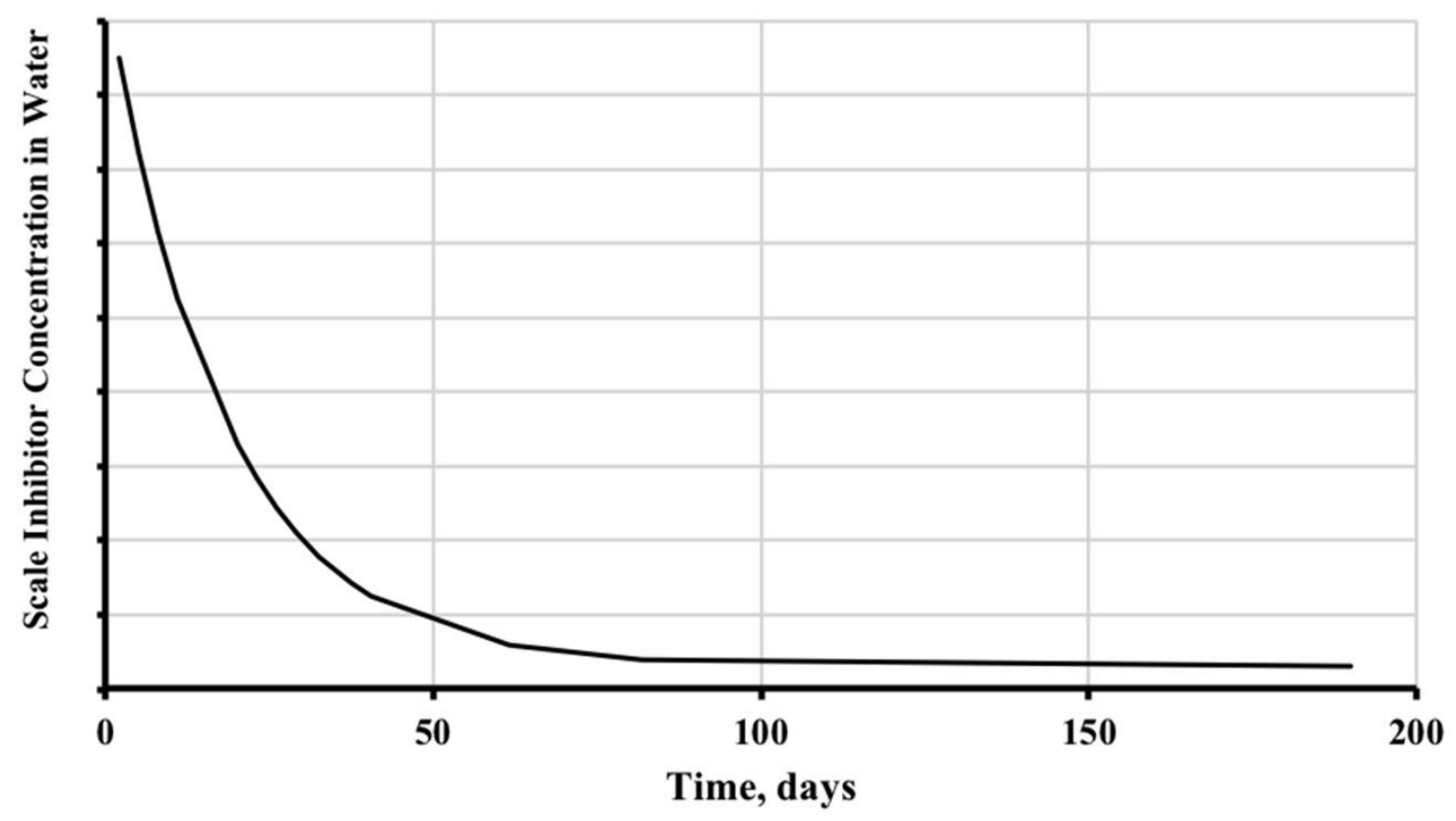

Figure 5. Typical curve of SI concentration change in the well water after squeeze.

In order to describe the SI concentration change in produced water with time after SI solution squeeze, we propose to use a formula applied in the Logarithmic Dilution Method in gas chromatography (the method was introduced by J.E. Lovelock in 1961 [20]).

Similarly to [20], after SI solution squeeze into a formation its concentration in well water could be described by the formula:

$$
C=A \cdot \frac{V_{\mathrm{SI}}}{V_{\mathrm{SW}}} \cdot e^{-\left(B \cdot \frac{Q_{\mathrm{w}}}{V_{\mathrm{SI}}+V_{\mathrm{SW}}} \cdot t\right)}
$$

Where $C$ - concentration of SI in water, $\mathrm{mg} / \mathrm{dm}^{3} ; V_{\mathrm{SI}}$ - volume of SI solution squeezed, $\mathrm{m}^{3}$; $V_{\mathrm{SW}}$ - volume of water squeezed, $\mathrm{m}^{3} ; Q_{\mathrm{w}}-$ well water production rate, $\mathrm{m}^{3} /$ day.; $t$ - time from well start up after squeeze, h; $A$ and $B$ - coefficients.

A production well of the Piltun-Astokh oilfield (Sakhalin shelf) was treated with SI SCW 85370 by squeeze method. $28 \mathrm{~m}^{3}$ of SI solution was pumped and squeezed into a formation followed by $194 \mathrm{~m}^{3}$ of water. After the well start up its average water rate was $352 \mathrm{~m}^{3} /$ day.

The concentration of the SI in the produced water was measured using the method developed. The $A$ and $B$ coefficients of formula (1) were obtained with a least square method so that the calculated chart of SI concentration change in time most accurately matches with the experimental data, $A=17171.4 ; B=0.03248$. Figure 6 shows the experimental and calculated (using (1)) curves of SI concentration change in time. Figure 7 shows data in semilogarithmic coordinates. 


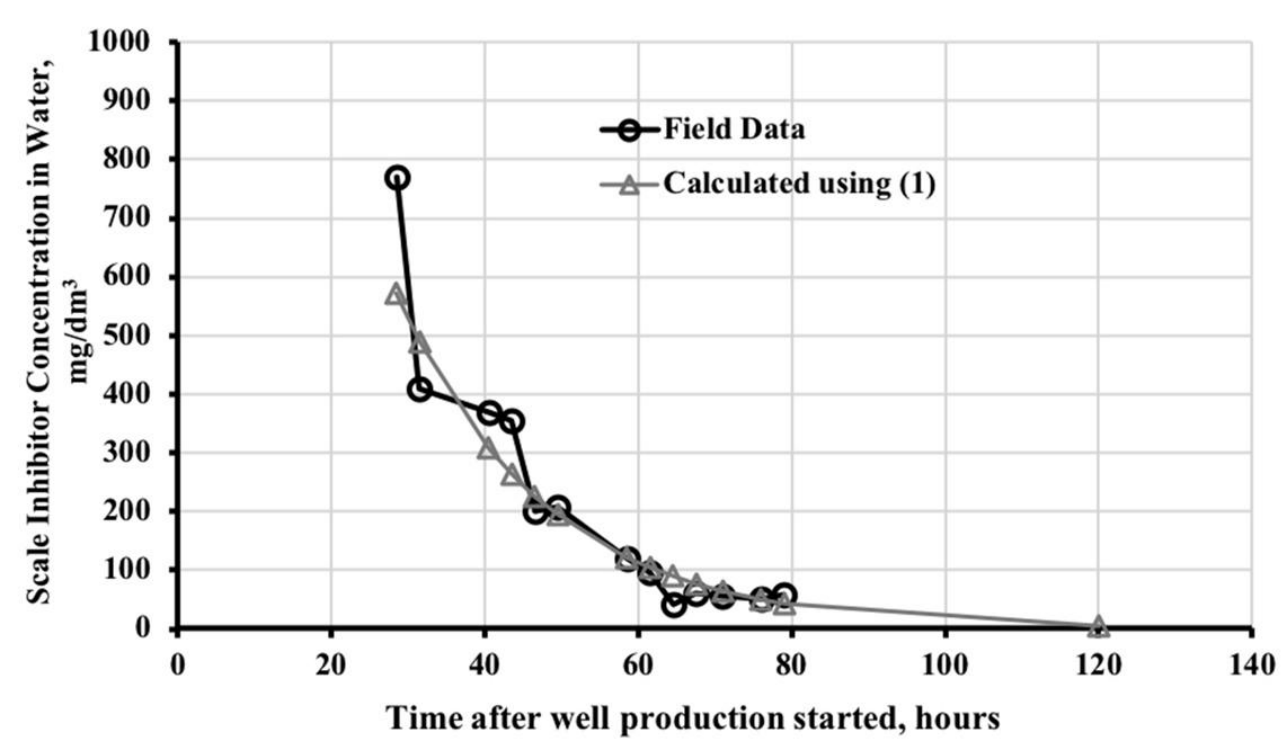

Figure 6. The experimental and calculated curves of SI SCW85370 concentration in water after scale inhibitor treatment.

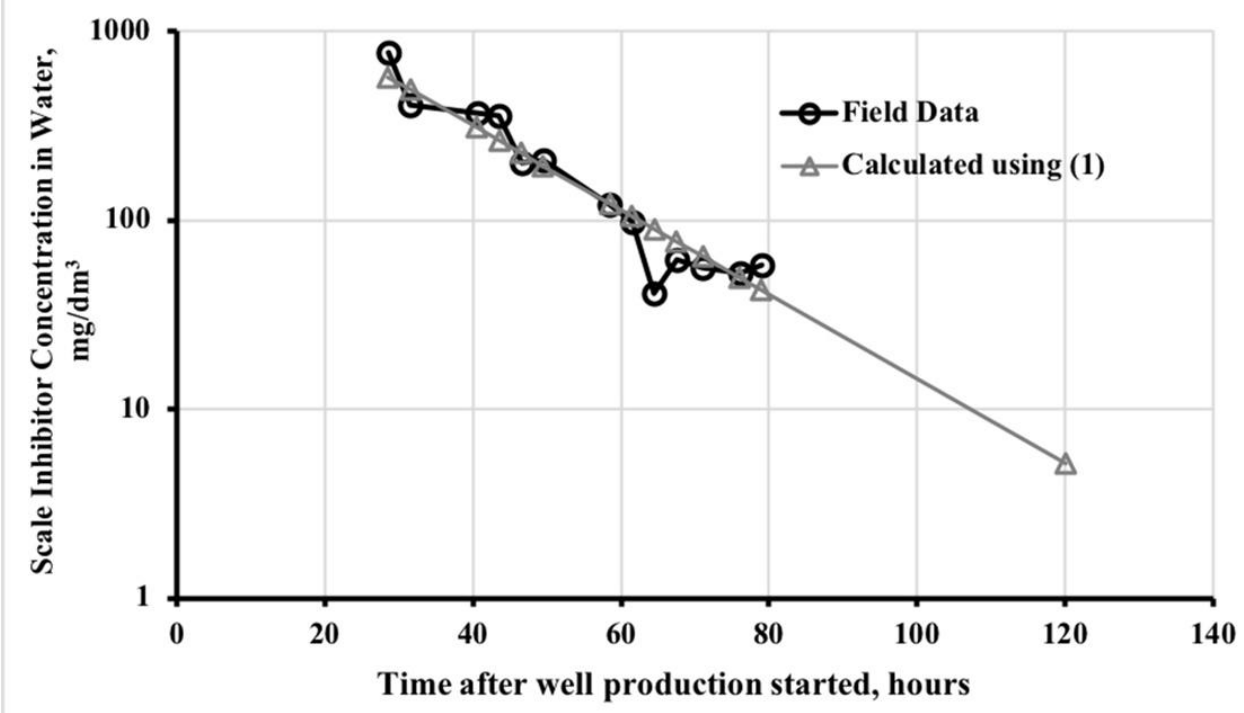

Figure 7. The experimental and calculated curves of SI SCW85370 concentration in water after scale inhibitor treatment (semilogarithmic coordinates).

As it is seen from Figures 6 and 7, the SI concentration change in time in produced water after SI squeeze treatment is well described by the suggested formula (1).

The use of the developed method for SI analysis and the formula (1) allowed us to make an important conclusion: the concentration of SI in the produced water drops below $\sim 1 \mathrm{mg} / \mathrm{dm}^{3}$ after $\sim 6$ days (Figure 7 ) from the well start up. As per chemical supplier data, concentrations of SI SCW85370 in water $\leq 1-2 \mathrm{mg} / \mathrm{dm}^{3}$ do not provide effective protection against mineral scale deposition. Therefore, effective scale inhibition of that well can be achieved for 5-6 days only after the well start up. However, SI squeeze treatment design in 
terms of SI water solution volume was performed to allow effective protection of the well for at least 3-4 months. Obviously, in the described case the absorption of SI SCW85370 by the formation rock was less than expected as per experience of application of that SI at other oilfields. The forecast made was fully confirmed - the concentration of SI in the produced water after 2 months from the well start up was less than the lower limit of the method detection.

\section{Conclusions}

For the successful application of a scale inhibitor, the concentration of the applied reagents in the water phase of an oil production system shall be monitored.

A method for the measurement of a polymeric scale inhibitor in water by high performance liquid chromatography with an UV-detector has been developed.

A formula for scale inhibitor concentration calculation in the produced water after SI squeeze treatment is proposed. The formula allows one to calculate the SI concentration at any point of time using the following data: the volume of SI solution squeezed, the volume of water squeezed, and the well water flow rate. It has been shown that experimental data is well characterized by the suggested formula.

\section{Acknowledgments}

The work was performed with the use of equipment of Far East center of structural surveys of the Institute of Chemistry, Far Eastern Branch, Russian Academy of Sciences.

\section{References}

1. A.N. Markin, R.E. Nizamov and S.V. Sukhoverkhov, Neftepromyslovaya khimiya: prakticheskoe rukovodstvo, Vladivostok: Dal'nauka, 2011, p. 288 (in Russian).

2. RD 39-0148070-026VNII-86, Tekhnologiya optimal'nogo primeneniya ingibitorov soleotlozheniy, SibNIINP, 1986 (in Russian).

3. L.A. Shangaraeva, Metody predotvrashenia otlozheniya soley $v$ neftyanykh skvazhinakh, Innovatsii v nauke: sb. St. po mater. XXVII mezhdunarod. nauch.-prakt. konf., Novosibirsk, SibAK, 2013, 24, no. 11, 163-168 (in Russian).

4. A.N. Markin, S.V. Sukhoverkhov and A.V. Brikov, Neftepromyslovaya khimiya: Analiticheskie metody, Yuzhno-Sakhalinsk, 2016, p. 212 (in Russian).

5. A.M. Kelland, Production Chemicals for the Oil and Gas Industry, CRC Press, 2009, $404 \mathrm{pp}$.

6. ASTM D6501-09, Standard Test Method for Phosphonate in Brines, ASTM International, West Conshohocken, PA, 2009, www.astm.org. doi: 10.1520/D6501-09

7. A.V. Brikov, A.N. Markin and S.V. Sukhoverhov, "Scale Inhibitor Analysis Methods an Analytical Overview", Oilfield Eng., 2018 (in press).

8. L.S. Ivashkevich, T.P. Karatayeva and A.S. Lyakhov, Rentgenograficheskie metody $v$ khimicheskikh issledivaniyakh, Minsk, isd-vo BGU, 2001, 131 pp. (in Russian). 
9. N.F. Losev and A.N. Smagunova, Osnovy rentgenospektralnogo fluorestsentnogo analiza, Moscow, Khimiya, 1982, 208 pp. (in Russian).

10. A. Smith, Prikladnaya IK-spektroskopiya (Applied IR Spectroscopy), Russian translation, Moscow, Mir, 1982, 382 pp. (in Russian).

11. Yu.A. Pentin and L.V. Vilkov, Fizicheskiye metody issledovaniya v khimii, Moscow, Mir, 2003, 683 pp. (in Russian).

12. B.I. Lirova and E.V. Rusinova, Analiz polimernykh kompozitsionnykh materialov: uchebnoe posobie, Ekaterinburg, Ural University, 2008, 187 pp. (in Russian).

13. R.A. Khmelnitskiy, I.M. Lukashenko and E.S. Brodsky, Piroliticheskaya massspectrometriya vysokomolekulyarnykh soedinenii, Moscow, Khimiya, 1980, 279 pp. (in Russian).

14. V.G. Zaikin, Mass-spectrometriya sinteticheskikh polimerov, Moscow, VMSO, 2009, 332 pp. (in Russian).

15. S. Tsuge, H. Ohtani and C. Watanabe, Pyrolysis - GC/MS Data Book of Synthetic Polymers - Pyrograms, Thermograms and MS of Pyrolyzates, Elsevier Inc., 2011.

16. F-Search System "All-in-One", Mass Spectral Libraries for Polymers and Additives, and Search Software. Operation Manual, Frontier Laboratories Ltd., 2014, 59 pp.

17. E.L. Styskin, L.B. Itsykson and E.V. Braude, Prakticheskaya vysokoeffektivnaya zhidkostnaya khromatografiya, Moscow, Khimiya, 1986, 284 pp. (in Russian).

18. K.S. Sychev, Prakticheskii kurs zhidkostnoi khromatografii, KOKORO, 2013, 272 pp. (in Russian).

19. N. Poynton, A. Miller, D. Konyukhov, A. Leontieff, I. Ganiev and A. Voloshin, "Squeezing Scale Inhibitors to Protect Electric Submersible Pumps in Highly Fractured, Calcium Carbonate Scaling Reservoirs", SPE No.115195, SPE Russian Oil and Gas Technical Conference and Exhibition, 28-30 October, Moscow, Russia. 2008.

20. J.E. Lovelock, "Ionization methods for the analysis of gases and vapors", Anal. Chem., 1961,33 , no. $2,162-178$. 